\title{
CONSIDERAÇÕES SOBRE MEIO AMBIENTE, DESENVOLVIMENTO ECONÔMICO E DIREITO.
}

\author{
João Paulo A. Vasconcelos ${ }^{1}$
}

\author{
Munir Jorge Felício²
}

RESUMO: A partir das principais questões atuais - a ambiental, a social e a humana, cuja gênese está na crise do conhecimento, este artigo reflete, criticamente e sem descuidar da interdicisplinariedade, sobre o desafio do século XXI, garantir a eficiência econômica, a conservação ambiental e a equidade social, ou compreender as fraquezas e implicações dos ecossistemas, de modo a conciliar sua utilização com os níveis de tolerância aceitos pela natureza" (AZEVEDO, 2008, p. 97). A despeito dos avanços creditados à economização do mundo guiado pela racionalidade tecnológica e pelo livre mercado, a sobrevivência humana está em risco. Faz-se, pois, imprescindível o debate paradigmático. A dinâmica econômica sempre pressupôs interação com o ecossistema, relação de dependência entre sistema econômico e meio ambiente. A finitude dos recursos naturais existentes, que geram um fluxo de serviços úteis aos seres humanos e sua exploração motivada pela necessidade de aumento da produção ante o crescimento populacional, e o estilo de vida próprio do modelo capitalista de produção, são fatores que justificam assertivas em torno da imposição de limite ao crescimento econômico. Mas à mesa de discussão do desenvolvimento planetário, põe-se, prioritariamente, a eficiência econômica. O conflito entre interesses tão relevantes despertou o Direito para a questão ambiental. No Brasil, situado como princípio da ordem econômica, a proteção ao meio ambiente impõe limite ao exercício da atividade econômica. Essa norma

\footnotetext{
${ }^{1}$ Mestrando em Ciências Jurídicas (UENP). Especialista em Direito Constitucional pela Escola Superior de Direito Constitucional - ESDC. Professor na Faculdade de Direito da Universidade do Oeste Paulista UNOESTE. joao.vasconcelos@agu.gov.br

${ }^{2}$ Doutor em Geografia; Docente do Mestrado em Meio Ambiente e Desenvolvimento Regional da Unoeste. munir@unoeste.br
} 
jurídica de direito fundamental, vincula a atividade do intérprete. O Estado brasileiro deve defender o interesse ao equilíbrio ecológico, essencial à manutenção e continuação da vida.

Palavras-chave: meio ambiente; desenvolvimento econômico; direito; sociedade.

\section{INTRODUÇÃO}

É manifesto que a sociedade mundial não conseguiu organizar-se a partir do desenvolvimento sustentável, assim entendido o que, promovendo, resgatando e tutelando a vida e sua qualidade, realiza a dignidade da pessoa humana.

Urge conciliar a produção, necessária á obtenção da qualidade de vida, e a proteção dos ecossistemas.

O Estado, notadamente o social, como é o caso do nosso país, deve romper com o pensamento único, a lógica do capitalismo que promove a exclusão social e a degradação do meio ambiente.

Biocêntrico ou (neo) antropocêntrico o paradigma, o certo é que a política econômica internacional, pública e privada, deve pautar-se na sustentabilidae que privilegia a vida, o desenvolvimento sustentável que dê sustentação ao ser humano.

No caso do Brasil, país emergente e de democracia tardia, além da crise de conhecimento, experimentamos a ética, a de legitimidade de representação democrática e a científica. A despeito da reponsabilidade ambiental perante os demais países, vivemos o dilema do antagosnismo entre desenvolvimento/crescimento econômico e proteção do meio ambiente. O gigante adormecido pode, quer e precisa crescer, levando ao crescimento seu povo.

E o instrumento para condicionar as políticas públicas e a atividade econômica privada ao tal desenvolvimento socioeconômico é o Direito. Não se trata de impedir a utilização dos recursos disponíveis nos ecossistemas nacionais, mas sim de direcionar a exploração ao bem comum, e não ao lucro e à extração e produção desenfreadas. $\mathrm{O}$ exercício da propriedade deve, segundo a Constituição Federal de 88 , atender à função sócioambiental. 


\section{CRISE DE CONHECIMENTO E DESENVOLVIMENTO SÓCIOECONÔMICO}

No centro dos debates sobre os processos de degradação sócio-ambiental, perda e preservação da biodiversidade e transição demográfica tem se instalado uma crise do conhecimento como gênese e ancoradouro e embates e discussões. Como epicentro epistemológico, ela vem desempenhando funções centrípeta e centrífuga para chamar a atenção dos cientístas e pesquisadores referente a urgente ruptura paradigmática, por não ser possível resolver os problemas atuais utilizando os mesmos paradigmas que os engendraram.

A crise do conhecimento indica que a humanidade caminha na direção do desenvolvimento de uma sociedade da ignorância apesar do avanço dos conhecimentos tecnocientíficos, como analisa André Gorz ao constatar que "a grande maioria conhece cada vez mais coisas, mas sabe delas e as compreende cada vez menos" (GORZ, 2005, p. 81. Itálicos no original).

As três principais questões atuais - a ambiental, a social e a humana - tem sua gênese na crise do conhecimento se constituindo uma realidade una. Trata-se de abordagens diferentes da mesma e única realidade a exigir interpretação interdiscipliar dada sua complexidade e abrangência. A unicidade delas implica em compreendê-las conjuntamente, pois os problemas gerados numa vertente repercute, direta ou indiretamente, nas demais, por se constituirem um sistema uno, complexo e indivisivel.

De tal maneira que, ou se soluciona todos os problemas, conjunta e harmonicamente, ou o colapso gerado por essa insustentabilidade que chegou até aqui persistirá ameaçando as gerações futuras. O desafio em garantir a eficiência econômica, a conservação ambiental e a equidade social implica em um desenvolvimento que seja ambientalmente sustentável, economicamente sustentado e socialmente includente

Essa ruptura paradigmática inverte a lógica capitalista ao impulsionar outra racionalidade com forma alternativa de produção econômica que não se desenvolve atrelada aos ditames das leis da acumulação do capital. Como não pode também ser concebida como uma racionalidade que não dialogue com o mercado. Mesmo que esse 
mercado tenha suas bases assentadase no sistema capitalista cujas forças produtivas se consolidam na predominância dos processos tecnológicos.

Eles se constituem nos implementadores da fluidez do capital de onde a sua expansão é garantida e preparada com a concentração do poder. Arrighi (2009) consegue demonstrar a pujança do capital em se apoderar do Estado como dois grandes processos interdependentes: a criação de um sistema de Estados nacionais e a formação de um sistema capitalista mundial.

A crise do conhecimento e a crise de civilização que se instalaram no último terço do século XX e que se desenvolveram no início do terceiro milênio, avançaram por causa do "fracionamento do conhecimento e pela degradação do ambiente, marcados pelo logocentrismo da ciência moderna e pelo transbordamento da economização do mundo guiado pela racionalidade tecnológica e pelo livre mercado" (LEFF, 2000, p. 19). De maneira que a realidade de opulência sem precedentes, segundo Sen (2008), propicia às pessoas hoje viverem "em média muito mais tempo do que no passado, [...], entretanto, vivemos igualmente em um mundo de privação, destituição e opressões extraordinárias" (SEN, 2008, p. 9).

$\mathrm{Na}$ grande aldeia global as diferentes regiões estão cada vez mais estreitamente unidas no campo das comunicações, do comércio e numa gigantesca permuta de alternativas difícil de imaginar um ou dois séculos atrás. A industrialização da agricultura promoveu ganhos de produtividade majorando a superfície que salta de 1 para mais de 200 hectares de área cultivada por um trabalhador. Contudo, a sobrevivência humana está em risco no longo prazo. E esse ecocídio como suicídio coletivo faz as decisões ganharem caráter de imprescindibilidade dada a necessidade de alterar os rumos e garantir o futuro das gerações, "ainda que muitos dos problemas ambientais que hoje presenciamos, ou que sabemos irão ocorrer em breve, sejam irreversíveis no curto prazo" (SÓGLIO, 2009, p. 311)

A imprescindibilidade do debate paradigmático poderá contribuir pela potencialidade dele fazer emergir, ao analisar a complexidade das questões acima descritas, o entrelaçamento de elementos novos e antigos, sem contudo, se descuidar de que o centro dos debates tem a crise do conhecimento como sua gênese e ancoradouro. 
A proposta metodológica sugerida por Felício (2011) defende a hipótese segundo a qual o confronto entre dois paradigmas pode elucidar os referencias teóricos, as ideologias, as intencionalidades e as opções políticas à medida que as discussões se intensificam. Aplicando a proposta metodológica tendo como centro do debate a crise do conhecimento e dela fazendo parte inerente a questão ambiental emergem duas concepções distintas entre o relacionamento ser humano e natureza.

O paradigma do antropoccentrismo compreende essa relação a partir do ser humano. Trata-se de uma compreensão advinda da cosmovisão grega em que as ações antrópicas são exercidas com a finalidade de dominar as forças naturais. São razões como essas que justificam a afirmação de que a terra é do ser humano como posse e propriedade. E, como tal, o relacionamento ser humano e natureza se desenvolve quando o ser humano faz da natureza "sua" despensa por fornecer todos os recursos necessários para o desenvolvimento da sua vida e como lixeira por depositar nela todos os seus rejeitos e dejetos.

O paradigma do bioccentrismo compreende essa relação a partir da vida, da qual o ser humano também faz parte. Trata-se de uma compreensão advinda da cosmovisão hebráica em que as ações antrópicas são exercidas com a finalidade de conhecer e de descobrir as potencialidades das forças naturais. São razões como essas que justificam a afirmação de que o ser humano é da terra - e, não o contrário. E, como tal, o relacionamento ser humano e natureza se desenvolve quando ele se empenha na exploração e no desbravamento e descobrimento das fontes dos recursos naturais necessários para o desenvolvimento da vida, como um todo e dele em particular. E, por isso mesmo, ele se desafia a ampliar esses recursos na medida do possível, tornando-os ilimitados para o seu bem-estar e da população mundial cuja tendência é aumentar cada vez mais.

A partir desse debate paradigmático novas abordagens ganharão significados distintos, como, por exemplo, analisar o meio ambiente e o desenvolvimento econômico.

\section{MEIO AMBIENTE E DESENVOLVIMENTO ECONÔMICO}


Só teremos resultados concretos se conseguirmos conjugar minimamente interesses tão diversos.

A frase é atribuída a Achim Steiner, diretor executivo do Programa das Nações Unidas para o Meio Ambiente - PNUMA, em entrevista concedida à Revista Veja ${ }^{3}$, às vésperas da Rio+20. Referiu-se à relação desenvolvimento/proteção ambiental. Esse diagnóstico da economia mundial não é recente, e a despeito de tratado em Estocolmo/1972, dando nascimento ao conceito de desenvolvimento sustentável, subsiste animado pela globalização e pelo consumo.

A dinâmica econômica sempre pressupôs interação com o ecossistema. Há uma relação de dependência entre sistema econômico (dependente) e meio ambiente, considerado este (em termos econômicos) um estoque de recursos naturais existentes que geram um fluxo de serviços úteis aos seres humanos (ANDRADE, 2008, p. 4). A partir do século XX o sistema econômico passa a impactar o ecológico de forma mais incisiva.

A finitude dos recursos naturais e sua exploração motivada pela necessidade de aumento da produção ante o crescimento populacional e o estilo de vida próprio do modelo capitalista de produção são fatores que, desde há muito, justificam assertivas em torno da imposição de limite ao crescimento econômico. Economistas clássicos como Adam Smith e Stuart Mill, entre outros, consideraram a hipótese de um estado estacionário (ANDRADE, 2008, p. 7).

A escola econômica neoclássica, embora reconhecendo a ocorrência de alguns problemas decorrentes da degradação ambiental, apostou no surgimento de novas tecnologias contra a escassez do capital natural e creditou ao crescimento econômico extra o aumento do bem-estar e do senso de justiça (ANDRADE, 2008, p. 8). A poluição, por exemplo, é mais uma externalidade ${ }^{4}$ negativa e como tal deve ser tratada.

Coube à crítica ambientalista nas décadas de 1960 e 1970 a proposta de um crescimento econômico zero, ante a exaustão dos recursos ambientais. Os desenvolvimentistas argumentaram que o desenvolvimento econômico, num primeiro

\footnotetext{
${ }^{3}$ Revista Veja [Editora Abril S/A]. São Paulo: Abril, ed. 2256, ano 45, no 7, p. 17; $20-21$.

4 "Externalidade é conceituada como todo efeito produzido por um agente econômico que repercute positiva ou negativamente sobre a atividade econômica, renda ou bem-estar de outro agente econômico, sem a correspondente compensação." (COELHO, 2009, p. 33). Essa gratuidade (falta de compensação) dos efeitos externos é considerada falha no mercado.
} 
momento nocivo ao meio ambiente, levaria, depois, ao aumento da renda per capita, do nível educacional e da consciência ambiental. Essa premissa não se pode creditar exclusivamente à economia desenvolvimentista. $O$ liberalismo humanista de Amartya Sen (SAWAYA, 2004) não abdica do livre mercado enquanto ambiente no qual os indivíduos devem ser tratados com igualdade, na medida em que têm liberdade de oportunidade, de escolha. Esta concepção não se afasta da idéia de Adam Smith sobre a convergência de interesses individuais: se cada um buscar os seus interesses individuais, guiando-se, no livre mercado, por uma mão invisível (do Estado), o interesse social (coletivo) é alcançado.

Atualmente, conquanto tenha surgido uma corrente econômica ecológica (economia ecológica) que condena o uso irresponsável dos recursos energéticos, por exemplo, e a desconsideração de sua finitude, subsiste a tensão entre dois interesses: a limitação à utilização dos recursos naturais finitos (e cada vez mais escassos) e a necessidade de produção e crescimento econômico para atender à demanda da sociedade mundial. Todavia, não se trata do antagonismo de outrora: desenvolvimento econômico (e social) versus meio ambiente e proteção ambiental. Entre eles há uma relação de complementaridade.

A história recente autoriza a afirmação segundo a qual 0 ideal do desenvolvimento sustentável está por vir, isto é, não passa de um compromisso selado em 1972 e ainda não efetivado. A falta de adesão dos Estados Unidos ao Protocolo de Quioto (1997 - redução da emissão de gases do efeito estufa) e os resultados da Rio+20 acenam para a necessidade de não se descuidar do debate e de se questionar sobre 0 papel do Estado e da coletividade da defesa do meio ambiente equilibrado.

\section{MEIO AMBIENTE, DESENVOLVIMENTO ECONÔMICO E DIREITO}

O desconserto de nosso tempo reflete uma crise da civilização sem precedentes, pela sua extensão e profundidade. O que a caracteriza é a perda de rumos, a falta de perspectivas, sensíveis nas diversas dimensões do inter-relacionamento humano e nas várias concepções em que assentam. (AZEVEDO, 2008, p. 13). 


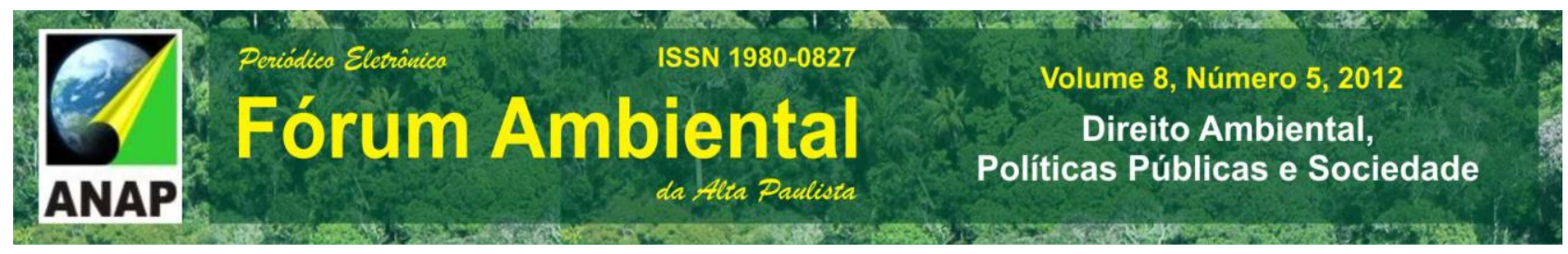

À mesa de discussão do desenvolvimento planetário, põe-se, prioritariamente, a eficiência econômica (produção e lucro), esquecendo-se que o desenvolvimento sustentável deve contemplar, preferencialmente, o social, o humano. Este o status desde o final dos anos 80 , quando as grandes potências econômicas adotaram o pensamento único neoliberal e passaram a impor suas decisões aos países em desenvolvimento ou subdesenvolvidos. Ganharam destaque a austeridade monetária, a disciplina orçamentária, a restauração da taxa natural de desemprego, a imposição de barreiras econômicas aos países pobres e, claro, o mercado.

E quanto ao meio ambiente, sua exploração irresponsável e ilimitada? Externalidade, como já foi dito. Quem paga a conta é o Estado e a sociedade. A visão dos "líderes mundiais" é turva, individualista, dissociada da realidade social.

Plauto Faraco de Azevedo adverte:

Mas é no meio ambiente que os resultados dessa concepção econômica se mostram mais avassaladores, embora, obviamente, o desastre ambiental tenha iniciado bem antes do advento do neoliberalismo. [...]

Hoje, os danos ecológicos se multiplicam. Diminui a camada de ozônio, a seca inclemente alterna-se com avassaladoras chuvas em vários pontos do globo, enquanto a temperatura da Terra eleva-se de modo inquestionável. (2008, p. 80).

E conclui: "O desafio do século $\mathrm{XXI}$ consiste em compreender as fraquezas e implicações dos ecossistemas, de modo a conciliar sua utilização com os níveis de tolerância aceitos pela natureza" (AZEVEDO, 2008, p. 97).

Afinal, vivemos a modernidade. Somos membros de uma sociedade de risco, de risco ecológico. Devemos, pois, discutir qual o risco aceitável, o que é tolerável em termos de sacrifício ambiental (e nosso), decisão que não deve ser totalitária, unitária, mas plural, democrática e justa.

As incertezas das nações quanto à definição - ou falta - de critérios racionais para utilização dos recursos ambientas em resposta à necessidade de crescimento, especialmente numa época marcada por sucessivas crises econômicas mundiais, reflete no Brasil. Surge a desconfiança sobre o acerto de políticas públicas econômicoambientais. A recente reforma do Código Florestal reanima a divergência: desenvolvimento social e agroeconômico ou retrocesso? 


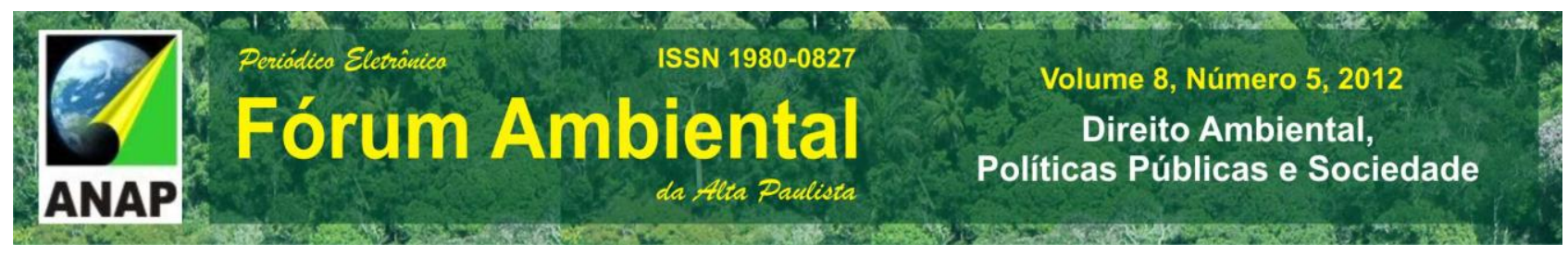

E à evidência, o conflito aparente entre interesses tão relevantes despertou o Direito para a questão ambiental (BENJAMIN, 1993, p. 13), forte nas suas funções ordenadora (EBAID, 2009) e mediadora.

A hermenêutica jurídica se encarrega de realizar a releitura da cláusula desenvolvimento, passando a entendê-la como utilização sustentável dos recursos ambientais. (AZEVEDO, 2008, p. 126).

A doutrina reclama a construção de um Estado de Direito Ambiental, "que venha a se adequar à crise ecológica e à sociedade de risco, possuindo princípios fundantes e estruturantes, contornos e metas para tentar minimizar os efeitos dos impactos negativos no meio ambiente." (BELCHIOR, 2011, p. 118)

A base jurídica para a efetivação desse modelo estatal já existe.

Essa nova hermenêutica - jurídica ambiental - parte, obviamente, dos princípios constitucionais, especialmente do princípio fundamental da dignidade da pessoa humana. Em nossa Constituição Federal, segundo José Afonso da Silva ${ }^{5}$ documento eminentemente ambientalista, inúmeros são os dispositivos constitucionais que cuidam das diversas relações entre Estado, coletividade, ecossistema e economia.

Para atender ao objetivo específico deste estudo, cabe destacar aqueles que estabelecem os vetores do desenvolvimento sustentável e da função socioambiental da propriedade e da empresa, a saber, numa ordem crescente, os artigos 5ㅇ, incisos XXII e XXIII (garantia do direito de propriedade e condicionamento de seu exercício à função social), 170 (aponta como um dos fundamentos da atividade econômica a livre iniciativa, fixa como finalidade a ser alcançada a existência digna e arrola dentre os princípios norteadores a propriedade privada a função social desta e a defesa do meio ambiente) e 225 , segundo o qual

Todos têm direito ao meio ambiente ecologicamente equilibrado, bem de uso comum do povo e essencial à sadia qualidade de vida, impondo-se ao Poder Público e à coletividade o dever de defendê-lo e preservá-lo para as presentes e futuras gerações [...].

Situado como princípio da ordem econômica e com acepção amplíssima a irradiar efeitos em todo o ordenamento constitucional, o princípio da proteção ao meio ambiente

${ }^{5}$ Direito Ambiental Constitucional. São Paulo: Malheiros, 1995, p. 26.

VIII Fórum Ambiental da Alta Paulista, v. 8, n. 5, 2012, p. 83-96. 
impõe limite ao exercício da atividade econômica, cumprindo ao agente econômico atender as diretrizes do desenvolvimento sustentável ${ }^{6}$.

Há na ordem jurídica econômica edificada na Constituição Federal de 1988 uma nítida intensificação de princípios sociais sobre aqueles imanentes ao regime liberalcapitalista, condicionando o comportamento do Estado e da coletividade.

Grau (2003) entende a função social da propriedade como função ativa, um poder-dever, uma imposição de comportamentos positivos, o condicionamento de um poder a uma finalidade. Sentencia:

o princípio da função social da propriedade impõe ao proprietário - ou a quem detém o poder de controle, na empresa - o dever de exercê-lo em benefício de outrem e não, apenas, de não o exercer em prejuízo de outrem. (GRAU, 2003, p. 213, grifo nosso).

No campo econômico (do exercício da atividade econômica), adverte o autor, esse novo regime jurídico da propriedade (não mais exclusivamente privado), ao condicionar seu uso ao bem-estar social (função ativa), não implicou a substituição do modelo capitalista, posto indissociável o regime da propriedade privada (capitalismo) para aferição acerca do cumprimento da função social. (GRAU, 2003, p. 207)

Assim, se a tutela constitucional da propriedade privada implica a proteção ao direito de exercer a empresa (atividade econômica de produção ou circulação de bens ou serviços organizada para a obtenção do lucro), inarredavelmente há vinculação do exercício deste direito ao cumprimento da função social, posto a esta funcionalização condicionando o direito de propriedade em sentido amplo. Por conseguinte, há interação entre sistema econômico e meio ambiente, considerando este um capital natural cuja finitude despertou a necessidade da limitação do crescimento econômico.

\footnotetext{
${ }^{6}$ Desenvolvimento sustentável é aquele que assegura as necessidades da presente geração sem comprometer a capacidade das gerações futuras de resolver suas próprias necessidades. A presente geração tem o dever de deixar para as futuras gerações um ambiente igual ou melhor do que aquele que herdou da geração anterior. (AMARAL, 2011, p. 1345). Segundo Cristiane Denari, "o direito do desenvolvimento sustentável teria a preocupação primeira de garantir a manutenção das bases vitais da produção e reprodução do homem e de suas atividades, garantindo igualmente uma relação satisfatória entre os homens e destes com seu ambiente." (apud AMARAL, 2011, p. 1347). Cançado Trindade "assinala que o desenvolvimento sustentável requer que se atenda às necessidades e aspirações do presente sem comprometer a habilidades de as gerações futuras atenderem suas próprias necessidades, fornecendo, assim, um possível vínculo entre o direito ao desenvolvimento e o direito a um ambiente sadio. (lbid.)
} 


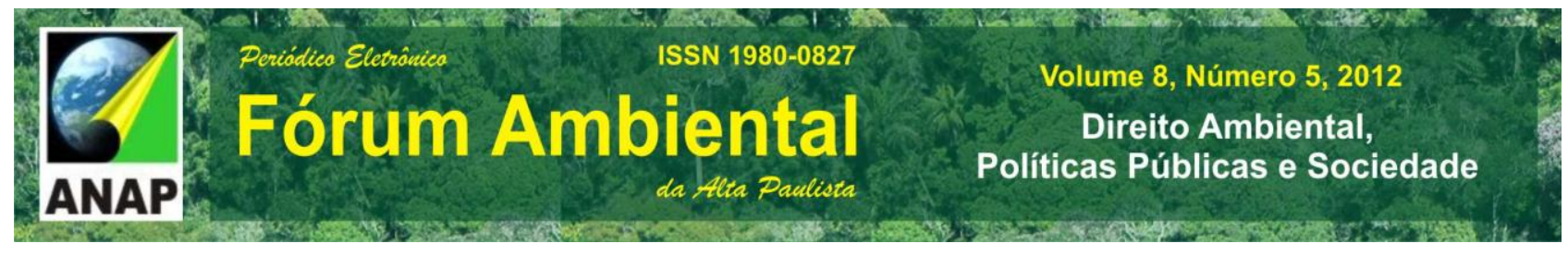

A busca irresponsável pelo desenvolvimento econômico levou à degradação ambiental, encontrando-se no Direito (local e internacional) a proteção reclamada e a garantia da sustentabilidade. Em suma, a tutela do meio ambiente exige a modificação do modo de ser da atividade econômica.

Por isso se diz que as normas ambientais encerram normas de direito econômico.

É o discurso de ANTUNES (2005), para o qual o conteúdo econômico do Direito Ambiental (DA) é evidente. Cita a Constituição Federal, que, a despeito de adotar um modelo capitalista e de certa forma liberal, posto edificado o princípio da livre iniciativa, arrolou entre os princípios gerais da atividade econômica a "defesa do meio ambiente", e a Lei no 6.938/81, a qual, dispondo sobre a política nacional de meio ambiente, está firmemente voltada para a compreensão da proteção ambiental como um elemento essencial da atividade econômica.

Antunes (2005) trata a legislação ambiental como instrumento de intervenção na ordem econômica, culminando por configurar um determinado padrão de apropriação dos recursos ambientais e de conduta dos agentes econômicos. Define Direito Ambiental DA - como sendo

[...] um direito que tem por finalidade regular a apropriação econômica dos bens ambientais, de forma que ela se faça levando em consideração a sustentabilidade dos recursos, o desenvolvimento econômico e social, assegurando aos interessados a participação nas diretrizes a serem adotadas, bem como padrões adequados de saúde e renda (ANTUNES, 2005, p. 9).

Outro não é o entendimento de Lafayete Josué Petter, que reconhece finalidade econômica na política nacional do meio ambiente e delimita da seguinte forma o conteúdo de desenvolvimento sustentável:

A exploração econômica a de ser realizada dentro dos limites de capacidade dos ecossistemas, ou seja, resguardando-se a possiblidade de renovação dos recursos renováveis e explorando de forma não predatória os recursos não renováveis, sempre no intuito de preservar os direitos dos que ainda estão por vir." (2008, p.273).

Esse autor expressa que o desenvolvimento diz respeito ao aumento da qualidade de vida dos integrantes da sociedade - desenvolvimento social. 


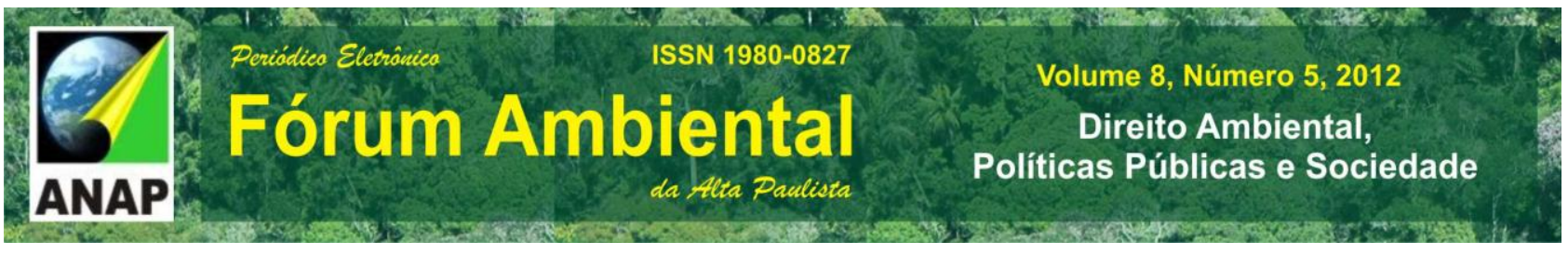

Segundo Antunes (2005), o Direito Ambiental apresenta três dimensões, humana, ecológica e econômica, às quais, a despeito de levar ao aparecimento de diferentes tensões, hão de ser compreendidas harmonicamente. Dentre os princípios do DA, arrola o princípio do direito ao desenvolvimento, cujo conteúdo permitiu-lhe afirmar que o meio ambiente brasileiro está fadado ao insucesso se não houver um acréscimo nos níveis de renda da população brasileira e uma melhoria substancial na sua distribuição, o que remete ao pensamento liberal e capitalista, porém "socializado".

A proteção ao meio ambiente, como direito fundamental agasalhado na Constituição Federal e princípio - constitucional - que informa a ordem econômica, deve vincular a atividade do intérprete. Quer o Direito que prevaleça sempre o interesse do equilíbrio ecológico, essencial à manutenção e continuação da vida (AZEVEDO, 2008, p. 132).

Além deste papel, cabe ao Direito Ambiental conferir proteção aos bens naturais, servir como mediador entre os diferentes agentes econômicos (na medida em que, ao afastar determinado bem da apropriação direta pela atividade econômica, propicia um equilíbrio na competição no mercado) e ser instrumento pelo qual o Estado realiza suas políticas ambientais, pois sua normatização decorre da necessidade do Estado regular atividades socioeconômicas, direta ou indiretamente, ligadas à degradação ambiental. (AMARAL, 2011).

\section{CONCLUSÃO}

Para pensar, criticamente, a questão ambiental a partir da sua complexidade e abrangência, torna-se indispensável localizá-la como componente de duas problemáticas contemporâneas: a crise de civilização e a crise do conhecimento. Nesse afã, as contribuições advindas das análises jurídicas contribuem significativamente, no sentido de garantir o mínimo ético sobre como o Direito e suas normas podem ser considerados. Todavia é urgente a necessidade da construção da consciência ecológica, por entender que apenas os expedientes jurídicos, apesar de necessários, não são suficientes para a devida proteção ao meio ambiente. Não basta só explicar como e porque acontecem as mudanças climáticas, como a destruição dos recursos naturais, do aquecimento global, do 
efeito-estufa e da destruição da camada de ozônio. É preciso transformar os valores culturais do ser humano, minimizar suas ações antrópicas e, com isso, alterar o seu modus vivendi.

\section{REFERÊNCIAS}

AMARAL, Paulo Henrique do. Tributação ambiental: contributo à política de desenvolvimento sustentável no Brasil. In: MACHADO, Paulo Affonso Leme; MILARÉ, Édis. (Org.) Direito ambiental: tutela do meio ambiente. São Paulo: Ed. Revista dos Tribunais (Coleção doutrinas essenciais), v. 4, 2011, p. 1343-1370.

ANDRADE, Daniel Caixeta. Economia e meio ambiente: aspectos teóricos e metodológicos nas visões neoclássica e da economia ecológica. Leituras de Economia Política. Campinas, (14): 1-31, ago.-dez. 2008.

ANTUNES, Paulo de Bessa. Direito ambiental. Rio de Janeiro: Lumen Juris, 2005.

ARRIGHI, Giovanni. O longo século XX Dinheiro, Poder e as origens de nosso tempo. 1aㅡ edição, 7ª̣ reim. São Paulo: Editora Unesp, 2009.

AZEVEDO, Plauto Faraco. Ecocivilização: ambiente e direito no limiar da vida. São Paulo: Ed. RT, 2008

BENJAMIN, Antônio Herman V. Função ambiental. In: BENJAMIN, Antônio Herman V. (Coord.). Dano ambiental: prevenção, reparação e repressão. São Paulo: Ed. Revista dos Tribunais, 1993, p. 9-81.

BELCHIOR, Germana Parente Neiva. Hermenêutica jurídica ambiental. São Paulo: Saraiva, 2011.

COELHO, Fábio Ulhoa. Curso de direito comercial. São Paulo: Saraiva, 2002, v. 2

EBAID, Ana Augusta Rodrigues Westin. A função social da decisão jurídica no direito contemporâneo. Colloquium Humanarum, Presidente Prudente, v. 6, n. 2, p. 11-17, jul/dez 2009. DOI: 10.5747/ch.2009.v06.n2.h066. Disponível em <http://revistas.unoeste.br/revistas/ojs/index.php/ch/article/viewFile/446/444> Acesso em 26 ago. 2012.

FELICIO, Munir Jorge. Contribuição ao debate paradigmático da questão agrária e do capitalismo agrário. 2011. 214 folhas. Tese (Doutorado em Geografia), apresentada no 
Programa de Pós-Graduação em Geografia. Universidade Estadual Paulista, campus de Presidente Prudente.

GORZ, André., O Imaterial Conhecimento, Valor e Capital. São Paulo, Annablume Editora, 2005.

GRAU, Eros Roberto. A ordem econômica na constituição de 1988: interpretação e crítica. 8a ed. São Paulo: Malheiros, 2003.

LEFF, Enrique. Complexidade, Interdisciplinaridade e Saber Ambiental. In: Interdiciplinaridade em Ciências Ambientais, PHILIPPI JUNIOR, Arlindo, TUCCI, C.E.M., HOGAN, D.J., NAVEGANTES, Raul (editores), São Paulo: Signus, 2000, p. 1951.

PETTER, Josué Lafayete. Princípios constitucionais da ordem econômica. $2^{a}$ ed. São Paulo: Ed. RT, 2008.

Revista Veja [Editora Abril S/A]. São Paulo: Abril, ed. 2256, ano 45, no 7, p. 17; 20-21. SAWAYA, Rubens Rogério. Liberalismo humanista: Amartya Sen e o desenvolvimento. Postado 19/3/2004. Disponível em: http://www.lead.org.br/article/ articleview/388/1/81. Acesso: 07-02-2012.

SEN, Amartya. Desenvolvimento como liberdade. 7aimpr. São Paulo: Companhia das Letras, 2008.

SILVA, José Afonso da. Direito Ambiental Constitucional. São Paulo: Malheiros, 1995.

SÓGLIO, Fábio Kessler Dal. O Desenvolvimento Rural no Brasil e na América Latina: como estão nossos projetos. In: Desenvolvimento Rural no Cone Sul. Desarrollo Rural en el Cono Sur, ALMEIDA, Jalcione e MACHADO, J.A.D. (orgs.) Porto Alegre: Associação Holos Meio Ambiente e Desenvolvimento (e-book), 2009, p. 311-336. 